\title{
La medicina antropológica de Heidelberg: Una perspectiva personal y algunas reflexiones
}

Fernando Lolas Stepke

En la presente comunicación el autor rememora sus años de formación en Heidelberg (Alemania Federal), en el contexto de lo que se ha dado en llamar "la Escuela de Heidelberg". A lo largo de sus líneas, el autor destaca la importancia de las ideas de su maestro, Paul Christian, así como de Ludolf von Kehrl y Viktor von Weizsäcker. El significado de la medicina antropológica y las relaciones intelectuales del autor con Paul Christian son objeto de detenido comentario.

medicina antropológica / Escuela de Heidelberg

Anthropological medicine in Heidelberg: A personal viewpoint and some thoughts

In this paper, the author recalls his years as a student at Heidelberg, Germany, in what has come to been known as the "School of Heidelberg". The author presents the ideas and significance of Paul Christian, his mentor, and the ideas of thinkers such as Ludolf von Kehrl and Viktor von Weizsäcker. Extensive discussion is dedicated to the meaning of the concept of anthropological medicine and to the intellectual relationship of the author with Paul Christian.

anthropological medicine / School of Heidelberg 
Me propongo presentar una perspectiva personal sobre lo que Pedro Laín Entralgo llamara, alrededor de los años cincuenta del siglo XX, la "escuela de Heidelberg". Quería con ello significar una unidad de propósito y una continuidad histórica en autores que aportaron a la mirada médica una amplitud y una profundidad a las que hoy, desde la lejanía de un futuro que ellos apenas entrevieron, podemos rendir tributo y enjuiciar críticamente. Al hacerlo, situaré mi presentación en un contexto personal y autobiográfico, ya que realicé parte de mis estudios en esa tradición, inspirado por el deseo de globalidad con que quería enriquecer mi incipiente carrera académica, entonces orientada a la investigación fisiológica del comportamiento. Deseo aclarar que la expresión "escuela de Heidelberg" también ha sido usada para referirse a la psiquiatría. Creo que en ambos casos es la vertiente antropológica del arte y la ciencia de la medicina lo que se ha querido destacar (Lolas, 1999a).

Heidelberg y la medicina antropológica que Laín Entralgo destacaba están inextricablemente ligados a mi evolución personal. Apenas me gradué de médico en la Universidad de Chile, en 1973, decidí continuar el trabajo que como ayudante del Departamento de Fisiología y Biofísica iniciara ya en el segundo año de mis estudios. Entonces nuestro tema era la actividad eléctrica cerebral durante los procesos de aprendizaje en conejos y monos ardilla y el deseo de entender los correlatos fisiológicos de los procesos psicológicos, aun en la forma sencilla que exige la indagación de laboratorio, me enfrentaba a interesantes problemas epistemológicos. Gracias a la benevolente ayuda de personas a las que guardo afecto entrañable y a mis méritos académicos pude realizar una formación mixta en que combiné la disciplina de la neurofisiología con la clínica psiquiátrica.

Hacia 1975, en que partí por primera vez a Heidelberg gracias a una beca del Servicio Alemán de Intercambio Académico (Deutscher Akademischer Austauschdienst), ya había decidido que la perspectiva que cultivaba en el Institut für Allgemeine Klinische Medizin el profesor Paul Christian, sucesor de Viktor von Weizsäcker y quien sería mi maestro, era la que yo requería para ampliar mis horizontes. He narrado algunas de las circunstancias de mi carrera temprana en otro lugar, destacando los principales temas a que me aboqué y la forma en que la experiencia de Heidelberg se insertó en lo que luego sería mi trabajo en la Universidad de Chile (Lolas, 1999b). Asimismo, en una entrevista que el psiquiatra peruano Renato Alarcón incluyó en su ya famoso libro Identidad de la psiquiatría latinoamericana bosquejé algunos de mis tempranos intereses y su evolución ulterior (Alarcón, 1990).

La amalgama entre la fisiología, concebida al estilo de Claude Bernard como el fundamento de la medicina 
científica, la clínica médica y la reflexión filosófica no se encontraba en ninguna parte mejor representada que en Heidelberg y la lectura de algunos estudios en que se combinaba la psicoterapia con la medición de variables corporales no hizo sino reafirmar mi convicción de que la vertiente psicosomática, en esa peculiar versión alemana, era lo que necesitaba para consolidar una línea de trabajo satisfactoria. He dejado en mi libro La perspectiva psicosomática en medicina una impronta de lo que fueron aquellos tempranos intereses, $\mathrm{mi}$ impresión del Heidelberg de los años setenta y algunas aportaciones teóricas que me acompañan desde entonces como saber implícito (Lolas, 1984).

Cuando llegué a Heidelberg encontré algo diferente de lo que había esperado, pero también algo que no imaginaba. Amplié mis trabajos a la clínica psicosomática, dirigida a la sazón por el profesor Walter Bräutigam, y a la clínica psiquiátrica, especialmente el departamento dirigido por el recordado profesor Hubertus Tellenbach, a quien unían con Chile ya antiguos lazos de amistad y trabajo.

Asimismo, incursioné en el estudio de la historia medieval y la historia de la medicina, uniéndome al grupo de trabajo en torno al profesor Heinrich Schipperges, con cuyo colaborador, Dietrich von Engelhardt, todavía hoy me unen lazos de estrecha amistad. Fue en la biblioteca del Instituto de Historia de la Medicina donde encontré algunos números de la revista Quirón, que diligentemente editaba y distribuía José Alberto Mainetti desde La Plata, en Argentina, publicación en la que se daban cita las humanidades y la medicina bajo la advocación del centauro sabio. Quienes me conocen me han oído mencionar más de una vez la paradoja de nuestro ser latinoamericano, que precisó que yo estuviera en Heidelberg para conocer los trabajos que se realizaban en la vecina Argentina.

El trabajo en investigación psicosomática pronto me llevó a incursionar en asuntos relativos al comportamiento no verbal (Lolas, 1978) y a la conducta verbal (Gottschalk et al., 1986), al desarrollo de métodos biométricos y psicométricos para la recolección de datos en condiciones significativas para los sujetos (Lolas \& Mayer, 1987) y al estudio de la tradición histórica que me acogía (Lolas, 1984). Largas y placenteras fueron las conversaciones que a lo largo de los años sostuve con muchas personas. Nadie negó su colaboración a mi deseo de conocer el pasado, a veces de difícil memoria, que nos enfrentaba a la época nacionalsocialista y a la evolución conceptual y empírica de la "medicina basada en la persona". Esta expresión, que invento para contrastar con la más conocida "medicina basada en pruebas" (evidence-based medicine) recoge el espíritu nuclear de esa escuela, cuyo principal exponente había declarado que la tarea de su doctrina y enseñanzas eran y deberían ser la (re)in- 
troducción del sujeto a la medicina y la biología.

Heidelberg, en los muchos años y en los largos días que ahora evoco, representó una estación importante en mi peregrinaje intelectual. Cierto es que la tradición, cuando yo la conocí, arrojaba solamente los destellos de un pasado más venturoso pero aún se mostraba, en la letra impresa al menos, con el macizo continente de algo inconcluso y merecedor de atenciones y cuidados. Con mi maestro Paul Christian debatimos muchas veces sobre lo difícil que resultaba encontrar interlocutores que supieran recrear algo del entusiasmo y la densidad intelectual con que aquellos renovadores de la medicina, entre los que él con modestia se incluía, habían abordado sus trabajos en los difíciles años de la pre y la posguerra.

\section{LAS FIGURAS Y LAS ESTACIONES DEL DESARROLLO}

He dejado en la nota prologal a mi traducción del último libro de Paul Christian una impronta del desarrollo histórico de la escuela de Heidelberg, centrándome en las que podrían llamarse sus personas importantes (Lolas, 1997b). Asimismo, en un artículo publicado en alemán, recapitulé algunas de sus orientaciones principales (Lolas, 2001).

No puedo dejar de mencionar también otros escritos en los cuales he desarrollado algunos de los puntos centrales y reconocido la deuda de mi pensa- miento a los autores de Heidelberg (Lolas, 1992, 1998). Tal vez la primera figura a la que deba hacerse mención, siguiendo la idea de Laín Entralgo, sea Ludolf von Krehl, cuyo nombre lleva hoy la Clínica Médica de la Universidad, en la Bergheimer Strasse. Krehl fue un hombre influyente en la medicina de su época, un renombrado profesor y alguien cuya opinión trascendía los límites de su especialidad. Su aporte fue considerable en muchos capítulos de la medicina interna, pero en este breve recuento interesa la adopción de un punto de vista personalista, situado en la perspectiva de la unidad de la persona, con que quiso reflejar los misterios de la individualidad del enfermo y del sano. Hizo suya la vieja sentencia hipocrática "no existen enfermedades sino enfermos" y la llenó de contenido mediante escrupulosas ilustraciones clínicas y el impulso que dio a los trabajos de brillantes discípulos. Para la medicina alemana de su época, no ha de haber sido frecuente que un profesor formado en la más rigurosa tradición anátomoclínica y fisiopatológica afirmara que la unidad de la persona es una dimensión espiritual. Tampoco sería de gran rememoración, por razones ajenas a su importancia, el reconocimiento que hizo del método biográfico de la patografía que entonces alumbraba en la obra de Sigmund Freud.

De Richard Siebeck rescato para esta presentación sumaria la reintroducción de la historicidad en la mirada mé- 
dica. No ya solamente como la clásica anamnesis, que precisamente alcanzaba su decantación y perfeccionamiento técnico en la primera mitad del siglo XX sino como biografía personal. Siebeck aportará esta dimensión diacrónica humanizada a la mirada del médico y sus escritos reflejarán el interés con que siguió las enseñanzas de su época, agregando al personalismo médico de Krehl la potente mirada histórica del devenir personal reconstruido en el encuentro entre médicos y dolientes.

Podría afirmar, si no me inhibiera la ausencia de una demostración más palpable, que en la tradición de Heidelberg se aprecia un fructífero contrapunto entre esas dos dimensiones de la "historia clínica", que con tan magistral mano recreara Laín Entralgo: la individualizante, que lleva a recrear una biografía (una patografía, en sentido estricto) y la específica, que reconstruye la realización, en un individuo particular, de una entidad mórbida (una species morbosae, al decir de Sydenham).

En las "mentalidades" que según el maestro madrileño jalonan la historia de la medicina, sin duda alguna que Heidelberg no solo representa la introducción del sujeto en la medicina - como dijeron sus epígonos- sino especialmente el sujeto humano bajo la forma de persona. De allí la justeza de la denominación de esa mentalidad como "antropopatológica" o, más simplemente, "antropológica". No debe olvidarse que en la construcción de una medicina dialógica, en el sentido de una praxis comunicativa según Haber- mas, el pensamiento médico recorrió las mentalidades anatomoclínica, fisiopatológica, etiopatológica, biopatológica (con la noción de organismo, especialmente en la obra de Kurt Goldstein) para llegar finalmente a esta concepción cualitativamente distinta de la medicina como una ciencia de acciones humanas.

En otro lugar me he referido a las sucesivas conquistas: del espacio, del tiempo y de la persona (Lolas, 1985a), siguiendo laxamente a Foucault, y me asombra comprobar cómo, heredando una tradición compleja, nunca supe desglosarla en sus constituyentes esenciales y que ahora, en este ejercicio reconstructivo de mi personal trayectoria (mis Lehrjahre y mis Wandeljahre, que quizá alguna vez sean rubricados por unos Meisterjahre), se me aparece con tal claridad. Casi podría decir que doy sentido, retrospectivamente, a mis afanes investigativos y docentes en la fisiología, la psiquiatría, la medicina psicosomática y la bioética gracias a la oportunidad de reconstruir mi biografía intelectual.

Casi no cabe dudar de que la personalidad central de la "escuela de Heidelberg", según Laín, sea Viktor von Weizsäcker. Sus abundantes escritos, su talento para la narración, su temprana familiaridad con la fase expansiva del psicoanálisis freudiano, su vinculación de campos disociados entonces, como la seguridad social y la clínica médica, unidos al influjo sobre un grupo de entusiastas discípulos, hacen su figura digna de recordación y análisis. 
Ya en 1927, en un artículo que escribiera para Die Kreatur, la revista que dirigiera, junto con Martin Buber y Joseph Wittig, había escogido hablar de medicina antropológica en lugar de medicina psicosomática. Indicaba así que lo psicosomático era una estación en el tránsito hacia una medicina de la persona y por la persona, en la que se destacaba su raigambre humanista y su aspiración antropológica. La evolución debía completarse con una auténtica antropología médica, esto es, una disciplina en la que prevaleciera el horizonte antropológico del arte de curar, ya no como trasfondo sino como esencial preocupación. En sus últimos escritos, por ejemplo la Pathosophie, von Weizsäcker sale de los cauces habituales de la literatura médica y aborda los problemas relacionados con la moral, la fe y la sociedad.

Sus relaciones con el psicoanálisis freudiano merecen mención, pues le envió a Sigmund Freud el manuscrito que luego se convertiría en el libro Körpergeschehen und Neurose, de 1932. Recibió de Freud una respuesta que indica la divergencia, pues en ella se advierte que los psicoanalistas que entonces se formaban deberían mantenerse alejados del cuerpo-objeto de la fisiología y concentrarse en las pulsiones y dinámicas del aparato psíquico. Sin duda alguna, las lecturas psicoanalíticas de von Weizsäcker le llevaron a apreciar la importancia de la vivencia y el lenguaje en cualquier teorización sobre lo humano y le permitieron reforzar la noción de que en el fondo todas las ciencias, las creencias y la filosofía, según el dictum de Goethe, confluyen en un solo punto, aunque parezcan separadas como oficios. Hablaba también de una ciencia virtuosa y consideró alguna vez al psicoanálisis como una "ciencia moral", prefigurando uno de los temas, ya tópico en su obra, cual es la moral práctica y la reflexión ética.

Paradójico es, a este respecto, que le haya tocado el difícil período del nacionalsocialismo. Mirado a la distancia, y tras muchas reiteraciones de la interpretación convencional sobre la inhumanidad de aquel régimen, es difícil arribar a un juicio ponderado sobre lo que él significó para la nación alemana y para quienes participaron de sus efectos y consecuencias. Un artículo de Viktor von Weizsäcker escrito en 1947, época en que se llevaba a cabo el juicio de Núremberg a los médicos que intervinieron en experimentos sociales e individuales, y que he traducido al castellano, se refiere con ponderación a la circunstancia histórica y a los valores morales que ella permitió develar. Así, por ejemplo, hablando de la eutanasia y los ensayos con sujetos humanos, se refiere a dos principios éticos, la solidaridad y la reciprocidad, haciéndoles jugar un papel importante, no solamente en las decisiones que afectan a las personas como individuos sino a la sociedad en su conjunto.

Aunque la interpretación fidedigna de sus aseveraciones requeriría un análisis profundo de la época y los giros idiomáticos entonces usuales, hay en este escrito una cierta ambivalencia y 
hasta ambigüedad respecto de la preponderancia de lo social o lo individual en decisiones de vida y de muerte. No es el caso entrar ahora en particulares detalles, pero quede esta anotación aquí para sugerir el valor de estos conceptos al momento de comparar tradiciones bioéticas.

Parte de mi trabajo en la villa Serbelloni, en Bellagio, apoyado por la Fundación Rockefeller, se dirigió a dilucidar los caminos diferentes de la bioética estadounidense y de la medicina antropológica en lo relativo a su sustento moral. Mi libro Bioética y antropología médica recoge los comienzos de esa reflexión (Lolas, 2000a), posteriormente continuada en diversos estudios y trabajos aún no publicados.

Tras varios años, reconozco la conveniencia, y aún la necesidad, de retomar el estudio de las vertientes históricas de movimientos que aparentemente persiguen metas semejantes con medios diferentes, y aprovecho esta ocasión de manifestaciones personales para invitar a otros a sumarse a esta tarea. Si no como protagonista al menos como partícipe de tales estudios, quisiera decir que propondrán sin lugar a dudas alguna renovación a nuestras monótonas disquisiciones bioéticas "latinoamericanistas", lamentablemente conducidas por personas que apuestan más a la estridencia de la consigna irracional que a la mesurada reflexión.

No es irrelevante destacar que la patografía nacida en el seno de la obra weizsackeriana difiere de la psicoanalítica en varios sentidos, en especial por el reconocimiento de un proyecto vital más allá de lo pulsional e instintivo y por la permanente referencia al entorno de los enfermos como constitutivo de su ser personas. Quede para otra apuntación la imagen de la persona que emerge de ambos trasfondos antropológicos, pues - como he repetido varias veces - el horizonte antropológico de una forma de medicina - que siempre le precede e inspira- no es evidente de suyo sino que debe ser descubierto, reconstruido y recreado. Como esto siempre acontece desde una particular perspectiva histórica, se renueva constantemente la apreciación de la obra pretérita y se la enriquece con nuevas dimensiones. Agrego esta reflexión para que se tenga presente cómo, desde mi condición de latinoamericano, miembro académico de una universidad estatal de un país pequeño, dedicado a los menesteres de la investigación científica y la docencia universitaria, he podido acercarme a esta tradición en una forma que sin duda no fue la misma que tienen o han tenido los euro-peos o los norteamericanos.

\section{HACIA UNA INTEGRACIÓN DE}

\section{PERSPECTIVAS EN TORNO A LA PERSONA}

Para mí, conocer al profesor Paul Christian constituyó un privilegio (Lolas, 2001). Cuando llegué a Heidelberg había sufrido una irreparable pérdida. Un hijo suyo había muerto trágicamente y su recuerdo gravitaba como un manto de niebla sobre la cotidianidad de ese hogar, sobre los rumbos que tomó el trabajo del profesor, ya próximo 
al retiro de la universidad, y sobre lo que yo podía esperar de su atención. Pasados los meses y los años, su figura permanece indeleble en el recuerdo, y la compañía de su esposa, el trato con su hija Petra y su esposo, los trabajos emprendidos tras su muerte y los que quedaron inconclusos a la espera de su continuación forman parte de mi vida.

En 1952, Christian publicó un libro titulado Das Personverständnis im modernen medizinischen Denken, monografía no superada en ambición y alcance, que resume las concepciones médicas sobre la persona humana. Se evidencia el influjo que sobre esa generación tuvo la presencia de Max Scheler, a quien Christian recordaba en sus aspectos humanos singulares y de cuyo ideario se nutrió parte de su formación filosófica. Se documenta allí un tránsito, no siempre fácil, desde las concepciones mecanicistas de la Grecia clásica a las especulaciones del barroco y finalmente a las novedosas aportaciones de un Friedrich Krauss o de los eminentes clínicos europeos con los que mi maestro se formara. Esa monografía tuvo sobre mí un efecto catalizador, pues, inspirado por sus sugerencias, decidí consagrar parte de mi tiempo a reflexionar sobre la vertebración histórica de nuestro oficio médico. Creo que en conjunto con muchos otros libros que leí despertó en mí la conveniencia de diseñar, sin prisa pero sin pausa, alguna forma de teoría "para" la medicina (y no "de" la medicina, pues la medicina es una construcción conceptual), de la que un primer intento - insuficiente por demás - constituyó mi libro Proposiciones para una teoría de la medicina (Lolas, 1992). En ese volumen, que obtuvo en Chile el premio de ensayo del Concurso del Consejo Nacional del Libro y la Lectura en 1993, reuní algunos artículos previamente publicados e intenté brindar una fugaz -y por definición, transitoria- perspectiva sobre mis preocupaciones teoréticas. Los elogiosos comentarios que recibí de muchos anónimos lectores y la envidiosa recepción de algunas mediocridades que siempre nos recuerdan nuestra contextura latinoamericana me alentaron a mantenerlo y releerlo con la finalidad de, alguna vez, acometer en serio la empresa de pensar la medicina y lo médico desde una perspectiva autónoma. Me quedan las palabras clave que usábamos como hitos: "patología teórica", "medicina antropológica", "subjetualidad versus subjetividad", entre tantas otras que debo contenerme de reproducir aquí.

\section{NOTAS SOBRE LA BIPERSONALIDAD}

Grande impresión me produjo, asimismo, el libro de Christian titulado Wesen und Formen der Bipersonalität, que se inicia con una frase que dice, más o menos, que hay realidades que no se configuran en el espacio interior del individuo sino que solamente en el intercambio, en el entre-espacio que se configura en el diálogo, llegan a tener vigencia. Muchas veces meditamos sobre el sentido que tiene, por ejemplo, el trabajo en común cuando es exitoso y bien logrado. Lo interesante de Christian y su 
grupo fue trasladar esta concepción abstracta al diseño de experimentos reales, y así pudieron demostrar cómo, en el proceso de usar una sierra, dos personas alcanzan una sincronía maravillosa y ajustan sus movimientos al logro común de derribar el árbol. Implicaba también este descubrimiento de que un enfermo que trabaja con una persona sana alcanza sorprendentes mejorías y hasta ajusta su ritmo al de la díada. Ni qué decir tengo que para una teoría de la conversación, o aun de la psicoterapia, la noción de bipersonalidad es de singular valor. Es más. Anclada en lo anatómico y lo fisiológico, la metáfora de la bipersonalidad puede hacerse bicorporalidad y aun biespiritualidad, permitiendo una reflexión ausente de bohemias y audaces construcciones sin sustento empírico. Por entonces, yo intuía que una lograda conversación es aquella en la cual ninguno de los hablantes sabe a ciencia cierta de dónde provienen las ideas, tampoco reclama autoría o protagonismo, pues el conjunto bipersonal parece funcionar como una unidad superior, dota de armonía y coherencia al conjunto y produce resultados inesperados no anticipables. $\mathrm{Mu}-$ chas veces recordé la sentencia de Herbart que dice "no hay un yo sin un nosotros" y me di cuenta de que nunca se es más yo, más individuo, que cuando se es parte de una unidad mayor. Que nunca, en realidad, se tiene verdadera identidad si no es por y con referencia a algún otro: se es hijo de un padre, amigo de un amigo, amante de una amada, discípulo de un maestro, en fin, siempre algo de algo en esa infinita trama de las relaciones sociales que constituyen el tejido de la existencia humana. Porque, como decía el sabio: "no man is an island".

\section{ACCIÓN Y VALOR}

Paul Christian había publicado en 1948, el año de mi nacimiento, un trabajo titulado "Vom Wertbewusstsein im Tun" ("De la conciencia de valor en el hacer"), que dedica al profesor Viktor von Weizsäcker con motivo de su sexagésimo cumpleaños. El ejemplar que ahora releo para esta recordación es muy viejo y su papel ya se destruye, indicio seguro de la antigüedad y señal de finitud que sobrecoge. Dice así su comienzo: "En la experiencia natural aparece el movimiento no como cosa (Sache) neutral sino como actividad que algo intenta, algo muestra y a algo conduce". Bastaría esta simple afirmación para comprender la intención de lo que sigue. El hacer, el movimiento humano no será objeto de una mecánica corporal. Será objeto de una reflexión dadora de sentido. Ya el maestro von Weizsäcker había hecho la distinción terminológica, hablando del sistema nervioso, entre Leitung, conducción, y Leistung, rendimiento. El movimiento que Christian quiere ilustrar no es simplemente el producto de las inervaciones neuromusculares, ni el resultado de los principios de la acción refleja. El movimiento a que su escrito se refiere tiene que ver con "realizaciones" o, más crasamente dicho, rendimientos. Pues no se mueve el hombre, y tampoco el animal, simplemente por mover- 
se. No hay un elan locomotif así como Bergson postulara un elan vital. Los organismos se mueven para algo y no solamente por algo. Obviamente, decimos de algunos movimientos que son instintivos, porque no hay antecedentes visibles de una intención o agencia consciente que permita modificarlos según la circunstancia y de otros que son motivados, porque descubrimos que solventan alguna deficiencia, sacian alguna necesidad o abren perspectivas de nuevas acciones (conductas apetitivas y actos consumatorios, al decir de la etología más clásica).

Lo importante de la perspectiva ilustrada en el opúsculo de Christian es que no solamente considera el movimiento desde una perspectiva "exterior". No solamente aparece en su trayectoria, duración y fuerza desplegada. Aparece, ante todo, en su dimensión interior o subjetiva, en lo que para el sujeto (y para quienes están en comunicación con el sujeto) aparece como "logrado", "correcto", "previsible", "adecuado". Este es el "valor" del movimiento, su perfección intrínseca, su inherente "virtud". Con ello, también su "verdad". El "buen" movimiento es siempre, como la buena palabra, verdadero. Recubre las intenciones del agente como una piel, es parte de su misma estructura. El hacer (o el movimiento, que es una de las formas del hacer) "valioso" o "valedero" tiene un cierto carácter de facilidad, naturalidad, "originalidad" (Ursprünglichkeit) y decisión (Entschiedenheit) que ya desde la intuición que le precede se experimen- ta, se "siente" y se anticipa. Produce, bien logrado en los deportes, una suerte de catarsis, no ex ore ni ex auditu, no por hablar ni por escuchar, sino por ver, ex visu. A ello podría adscribirse el placer de ver al deportista eximio o al ejecutante virtuoso. El espectador anticipa la posibilidad del yerro, de la falla, y se asombra y deleita con el logro. He ahí un valor que llega a la conciencia como lo correcto, lo justo, lo apropiado.

Podría detenerme in extenso en la relación que estas reflexiones de Christian inspiran para la consideración del arte, tanto de aquel que transcurre en la duración del tiempo —como la música- como del que aparece simultáneo en muchas formas de sensorialidad - como la escultura, intemporal pero rica en sensaciones visuales y táctiles. Pero metafóricamente hablando, para mí fue siempre atractivo aplicar esta concepción a la acción genérica humana, y hacer notar que la buena acción es siempre aquella que da plenitud a la intención, la colma de resonancias y placeres, produce en los demás una suerte de armónico y placentero regocijo. La acción moralmente buena es la acción de un agente que hace lo justo, lo apropiado, lo logrado y lo bueno. Extendida al espacio de la biografía, de las esencias que trascienden y se manifiestan en la vida humana, cabe recordar a Chaucer, que alababa en una mujer el ser "mujeril" y en un caballo el ser "caballar". La virtud consiste en la perfección inherente a una idea modélica, un eidos, un tipo, una especie, una forma única de ser. He ahí, sin duda, un fundamento de 
la intuición moral, que oscila siempre entre la ética (racionalización de lo que debe hacerse) y la estética (racionalización de lo que debe amarse). Tal vez la disociación entre ambos polos, constante en las tensiones dramáticas de la literatura, las ciencias y otras artes, permitiera atisbar algo de las complejidades de la vida y sus trastornos, de la salud y de la enfermedad.

\section{LAS CONVERSACIONES Y SUS PRODUCTOS}

Se hizo costumbre reunirnos los jueves con Paul Christian a hablar de medicina antropológica. Al llegar a su casa primero y luego a su retiro del "Augustinum" en Boxberg-Emmertsgrund ya estaba preparado el café y las galletas. Yo solía llevar algún apunte que resumía lo que hasta ese momento habíamos debatido o bien un libro que estuviera leyendo o que, tomado en préstamo de la biblioteca del profesor, debía ser devuelto. Me sentaba siempre en el mismo sillón. Tras comentar una que otra noticia reciente, generalmente del mundillo académico, empezábamos con alguna formulación provocativa que tuviera relación con lo antropológico en medicina y en las ciencias.

En realidad, para hablar de medicina con adjetivos hay que olvidar la medicina. $\mathrm{O}$ más bien retornar a los orígenes del arte de curar, el cual si fue técnica en sus comienzos, no lo fue de instrumentos y artilugios sino de percepciones, persuasiones y relaciones humanas. Ese horizonte antropológico, postsensorial pero preconceptual, es el reino del sensum communis, aquel que consagraran los "aforismos" hipocráticos. Porque medicina eficaz también es la de los tópoi, los lugares comunes, las consejas de la abuela y la vecina, la taumaturgia del curandero del pueblo, la palabra bella y sanadora del que escucha con el corazón. Medicina no es solamente, ni siempre, ciencia y técnica, sino trato humano, comprensión sapiente.

El privilegio de nuestras conversaciones consistía en la libertad de discrepar y de decir todo lo que se sentía o pensaba frente a un determinado asunto. La versación de Christian era muy amplia pero me dejaba el protagonismo en temas neurofisiológicos, que empezamos a discutir con fruición cuando acometió la empresa de escribir el que sería su último libro, Anthropologische Medizin, en cuya redacción final participé con entusiasmo y satisfacción. Pasajes hay en ese libro que hubieran requerido más abundantes discusiones y que, al momento de verterlos al español, exigieron de mí la autodisciplina necesaria para no caer en la tentación de modificarlos (Christian, 1997). Trozos completos quedaron para una revisión que nunca se produjo. Partes tiene el volumen que la ciencia fisiológica y los avances de la investigación médica han revisado y cambiado. Pero el conjunto es armonioso y adquiere para mí el carácter de un documento y de un testimonio. Al releerlo, redescubro la que fue su intención primigenia $\mathrm{y}$, en cierto modo, original: 
constituir una especie de "guión" (Drehbuch, screenplay) para nuestras conversaciones. El texto, que se gestó en, para y por nuestros diálogos, debía indicarnos cuándo proseguir una corriente del pensamiento, cuándo detenernos a contemplar un concepto, cuándo inventar un constructo para decir lo que no había sido expresado, cuándo recapitular el pensamiento ajeno, en fin, cuándo poner a punto nuestras armas persuasivas o disuasivas. Años después, durante la traducción, me sorprendí a menudo en ademán de continuar escribiendo sobre alguna idea que reconocía en el texto y tuve que contenerme para no tomar la pluma y "dalle fin" — según diría Cervantes- a un párrafo que ya venía petrificado en la expresión del profesor y que, en rigor, no correspondía al traductor modificar. Con ello quiero decir que fueron muy escasas las licencias, que hubo, en la versión castellana y, cuando fue necesario acortar algunos pasajes, se hizo consciente de las implicaciones y efectos y nunca se vulneró la intención. Este trabajo me recordó la inefable experiencia de producir textos en conjunto, que solamente en contadas ocasiones de mi vida he podido tener. Sucede que allí se realiza aquello de la multiplicidad infinita de los significados. Nunca existe un sentido canónico en un texto. Tantos sentidos hay cuantos lectores que lo recreen. Y a medida que pasa el tiempo, las significaciones originarias abren su tesoro de resonancias, multiplican las potencialidades, hacen inalcanzable la plenitud del significado.
Muchas veces, en la conversación, afloró la tradicional distinción que existe en la medicina desde los tiempos del Canon de Ibn-Sina (Avicena): la teoría y la práctica. Un saber teorético, si algo, tiene por misión, "hacer ver", pero para lograrlo, debe antes formar a sus destinatarios en alguna forma de "saber ver". La forma práctica (o "aplicada") de toda disciplina es un "saber hacer" que está precedido por "hacer saber" (o "enseñar"). Entre "saber ver" y "saber hacer" se mueve la empiria metódica de las ciencias, tanto las de objeto como las de acciones. Y aunque sigue siendo para mí evidente que la medicina es una ciencia de acciones y no de objetos, una Handlungswissenschaft (o, como también suele decirse, una praxiología) más que una Objektwissenschaft, siempre he tenido por bueno al maestro que además de buenos ejemplos sabe dar buenas razones y argumentar con limpieza en momentos de desacuerdo (Lolas, 1996). Es posible que el momento "aplicado" o "práctico" tenga más relevancia en algunos campos que en otros, pero existe en todos.

Yo quiero destacar aquí cuánto de conocimiento implícito se hizo entonces entraña de mi experiencia, y cuánto de conocimiento explícito fue críticamente examinado. Los teoremas de toda práctica están a veces axiomáticamente embebidos en la realización cotidiana, esa que obliga a preocuparse de lo urgente en lugar de lo importante, al punto de que los practicantes del oficio en algunas ocasiones dan por ver- 
dadero el uso continuo y no el uso juicioso. Muchos debates sobre lo que se llama standard of care o best proven treatment - que tantos problemas causan al juzgar la ética de la investigación médica - se verían auxiliados por una mejor reflexión sobre los orígenes del conocimiento vigente y las informaciones sobre las que se construye.

Uno de los temas que más perdurable memoria ha dejado en mí fue la distinción que hicimos entre trabajar "en" personas y trabajar "con" personas, en el entendido básico de que la acción médica, por definición, es terapéutica, es decir, se orienta a ayudar a quien precisa ayuda. Muchas veces, en los años siguientes, he vuelto a esta distinción, que juzgo importante al momento de discernir entre una investigación terapéutica y una investigación no terapéutica, tal como propuso la declaración de Helsinki de 1964. Más que el beneficio individual, distingue al acto terapéutico investigativo, que se hace “con" la participación del doliente y su vital interés en la empresa común. Una buena alianza terapéutica, como se asegura de continuo, es fundamental en las psicoterapias. Que de allí se pueda obtener conocimiento generalizable y renovación disciplinaria, metas de la investigación, es tarea y talento del profesional. La investigación "en" (y no “con") personas, reduce a estas al plano de los animales de laboratorio y las instrumentaliza. No quiere decirse que la instrumentalización sea en sí misma mala, por ubicua y necesaria a veces en la tradición de la medicina paternalista (beneficencia sin autonomía), pero puede a veces estar en un contexto de lesión a la dignidad y la autonomía.

Otro tema en el cual el profesor tuvo interés, obviamente por sus estudios y escritos previos, fue el que laxamente se dejaba entonces englobar bajo los conceptos, amplios pero impropios, de "conducta no verbal" y "comunicación no verbal". Yo llegué al tema por la necesidad de tener una amplia teoría de la comunicación y armonizar esa dimensión comportamental llamada conducta manifiesta (overt behavior) con la investigación psicofisiológica (fisiología con "sentido" para el sujeto humano) y la conducta encubierta (covert behavior), el ámbito de la vivencia, el lenguaje y la fantasía. Ese tema me llevó a leer y estudiar a los autores más diversos y con todo el material acumulado, más unas cuantas reflexiones, produje incontables páginas de textos algo confusos en inglés y alemán, que un buen día se me ocurrió someter a la consideración del profesor Christian, básicamente (y perdónese lo trivial del motivo) para que viera en qué andaba yo ocupado cuando no me comprometían las rutinas de la institución. El profesor tomó mi texto y lo guardó en una gaveta de su escritorio, con lo cual me di por satisfecho, pues mi afán mostrativo había sido recompensado. Mas a los pocos días, Christian me mandó llamar $\mathrm{y}$, teniendo enfrente mis papeles, mientras miraba por la ventana de su despacho hacia la Bergheimer Strasse, me dijo: “HHa pensado publicar esto?”. A lo que honestamente respondí que no, 
que eran apuntes, que no fuera a pensar que allí estaba todo mi esfuerzo y mi habilidad. El profesor asintió. Dijo que, efectivamente, el material era demasiado abundante y todavía tosco, pero que, si yo quería, él podía designar a alguien que me ayudara a ponerlo en un mejor alemán $\mathrm{y}$, de paso, discutir algunos puntos obscuros. Sin pensarlo dos veces, accedí y fue de ese modo como trabé contacto con el psicólogo Hans Ferner, con quien publicamos un artículo que debía inaugurar una serie que nunca se gestó (Lolas \& Ferner, 1978). Ese primer trabajo postulaba la noción de "conducta implícita" y era un desarrollo de lo que yo había leído. Reconozco que el producto se empobreció al prepararlo para la publicación. Si bien el psicólogo ayudó con el idioma, no aportó ideas. El producto vino a ser algo de lo que puedo hoy dar razón pero no fundamento, pues no tuvo eficacia en mi trabajo diario ni generó continuidad de intereses. Es verdad que publiqué muchos otros artículos sobre ese tema, muchos estudios empíricos sobre conducta y comunicación no verbal y verbal, pero la línea originada en esas disquisiciones originales no se mantuvo ni se desarrolló. Debo reconocer que a ello contribuyeron no poco la ingente abundancia de materiales, la vastedad de la empresa, la insuficiencia de mis recursos en los ámbitos de la lingüística y la semiótica y la presión de otros intereses. Sin embargo, de aquella empresa guardo un recuerdo y el deseo de recuperar lo entonces aprendido no me abandona.
Un tema sobre el que conversamos largamente fue la noción de estrés. Esta palabra de la lengua inglesa había ganado, ya entonces, el carácter de una "palabra clave" o "palabra llave", porque parecía indicar más que su simple denotación y abrir derroteros amplios a la investigación. En realidad, cuando pude ver al propio acuñador del término en su acepción médica, el investigador húngaro-canadiense Hans Selye, me impresionó su versatilidad verbal, su capacidad para hablar en muchos idiomas y, sobre todo, la simplicidad de su pensamiento. En realidad, los conceptos fértiles en las ciencias, como los escudos de armas, mientras más útiles y más antiguos, más simples. Es cierto que el tema estrés se complicó enormemente cuando salió de la esfera propiamente biológica en que Selye lo había situado y muchas facetas del concepto, en sus versiones psiquiátrica y médica, son tan amplias que hacen dudar de su utilidad, máxime si la palabra ya traspasó las fronteras de los especialistas y es parte del léxico común. Un libro que preparamos con Horst Mayer, colaborador de Christian y director de una unidad de investigaciones sobre el estrés, da cuenta de esa diversidad (Lolas \& Mayer, 1987). Con Christian elaboramos el término en el sentido de una "patología teórica", denominación que dimos a nuestras disquisiciones (Christian \& Lolas, 1985) y que nos llevaron a una relectura cuidadosa de los escritos norteamericanos sobre psicosomática y a un enjuiciamiento del "modelo biopsicosocial", entonces proclamado como enorme avance (Lolas, 1985b). 
De allí partimos a conversar sobre el tema del cuerpo y el espíritu, el que en la lengua alemana presenta una complejidad especial por las connotaciones diversas de las palabras que en español traducimos por "cuerpo": Leib, Körper. Llegamos a elaborar una postura que denominamos "teoría de las correspondencias", inspirados en la escuela weizsäckeriana y en lecturas amplias (Lolas \& Christian, 1990). Todavía hoy pienso que acertamos al menos en concordar una postura ni demasiado reduccionista ni demasiado espiritualista ni excesivamente dualista. Apelativos todos que de alguna manera u otra tiñen las concepciones sobre esta materia y permiten a legos y sabios pontificar sobre muchos asuntos, incluida la vida moral. Para nosotros fue interesante el diálogo entre Karl Popper y John Eccles y la curiosa resurrección del dualismo que allí se presenta. Determinante, en el ejercicio práctico de la medicina, es lo que von Weizsäcker había llamado "principio de la puerta giratoria" (Drehtürprinzip), el cual en términos simples describe la relativa ceguera de lo "espiritual" cuando se habla en lenguaje "corporal" y viceversa, de modo que la consideración conjunta y global de ambos en forma simultánea es difícil y punto menos que imposible. Se "recorre" en un círculo figural (Gestaltkreis), círculo fructuoso y no vicioso, lo perceptual y lo motor, lo sensorial y lo anímico, de modo tal que es el modo como hablamos de ciertas experiencias, las conclusiones que sacamos de ese hablar y los "intereses" que nos animan al hablar o las intenciones que tenemos lo que termina definiendo qué es cuerpo, qué es espíritu, qué es persona humana. Este discurso poiético crea los objetos y las acciones, fusiona hablante con lenguaje y produce esos discursos propios de las ciencias, que literalmente "crean" aquello de lo que hablan.

\section{UNA ESPECIE DE BALANCE PROVISIONAL}

Mi recuerdo heidelbergensis nunca me abandona cuando debo estudiar acerca de la medicina y la terapéutica. Me enseñó que aun la más potente de las tradiciones termina por extinguirse y que el tiempo no vuelve ni tropieza. Algunas sociedades - como la Viktor von Weizsäcker Gesellschaft — se han dado a la tarea de continuar el pensamiento de la vertiente antropológica, pero al momento de hacer un balance y de estudiar cuánto de todo ello se hizo entraña de las prácticas, se descubre que ha sido aún poco. Releo algunos pasajes del libro que publicara el profesor Peter Hahn, sucesor de Christian en la cátedra y el instituto de medicina clínica general, también Ordinarius en Heidelberg, y encuentro una ingeniosa forma de presentar "texto" y "contexto" para enseñar la técnica de la anamnesis en una perspectiva antropológica (Hahn, 1988). El libro no gozó de popularidad. Fue en cierta forma ignorado, como ignoradas han permanecido muchas intuiciones.

Para mí, los temas conexos de la praxis médica en sus diferentes formas, y el problema del diagnóstico en sus 
múltiples resonancias, fueron inspirados por mi contacto con esa tradición atemperado por mi trabajo de investigación en psicofisiología (Lolas, 1985c, 1994). Durante los años que siguieron a mi permanencia en Heidelberg volví a aquella universidad a trabajar con distintas personas, siempre con la generosa ayuda de la Fundación Alexander von Humboldt. ${ }^{1}$ La orientación integral ("holística", como dirían algunos) del pensamiento que había conocido y desarrollado se expresó en muchos de mis escritos y trabajos y concluiría llevándome a la bioética (Lolas, 1997, 2000b, 2002a, 2003, 2004; Lolas \& Agar, 2002), a la cual ingresé por deriva casi natural de mis intereses. Esta disciplina constituye, a mi juicio, la decantación de la intención dialógica que late bajo la tradición antropológica en la medicina y las ciencias y desde su vertebración interdisciplinar es posible la interpelación de muchos saberes y muchas prácticas (Lolas, 1998, 2001, 2002b).

No creo absurdo decir que está por trabajarse el inmenso legado de la escuela de Heidelberg a la preocupación bioética y que parte de mis esfuerzos se han dirigido a establecer algunos paralelos y, sobre todo, a potenciar los respectivos ámbitos de la bioética estadounidense y de la antropología médica alemana, con intuiciones que en parte están aún por inventarse y valorarse.

\section{REFERENCIAS}

Alarcón, R. (1990). Identidad de la psiquiatría latinoamericana. México DF: Siglo XXI.

Christian, P. (1997). Medicina antropológica (prólogo y notas de F. Lolas). Santiago: Universitaria.

Christian, P. \& Lolas, F. (1985). The stress concept as a problem for a theoretical pathology. Soc. Sci. Med (Oxford), 21, 1363-1365.

Gottschalk, L. A.; Lolas, F. \& Viney, L. (Eds.). (1986). Content analysis of verbal behaviour. Significance in clinical medicine and psychiatry. Heidelberg-Nueva York: Springer Verlag.

Hahn, P. (1988). Aerztliche Propädeutik. Berlín-Heidelberg-Nueva York: Springer Verlag.

Lolas, F. (1984). La perspectiva psicosomática en medicina. 2. ${ }^{\mathrm{a}}$ edición. Santiago: Universitaria, 1995.

Lolas, F. (1985a). Del espacio, el tiempo y la persona. En: Lolas, F. Notas al margen. Ensayos. Santiago: Editorial Cuatro Vientos, Colección Travesía.

Lolas, F. (1985b). The emergence of the biopsychocial approach. Soc. Sci. Med. (Oxford), 21, 1337.

1 Mi primera estancia en Heidelberg fue apoyada por el Deutscher Akademischer Austauschdienst (DAAD), Servicio Alemán de Intercambio Académico, e indirectamente por la Universidad de Chile, que me concedió entonces un permiso remunerado para perfeccionar mis estudios durante dos años. 
Lolas, F. (1985). The psychosomatic approach and the problem of diagnosis. Soc. Sci. Med (Oxford), 21, 1355-1361.

Lolas, F. (1988). Mehrdimenzionale Medizin. Medizinethische Materialien, Heft 21, Bochum, Zentrum für Medizinische Ethik Bochum.

Lolas, F. (1992). Proposiciones para una teoría de la medicina. Santiago: Universitaria.

Lolas, F. (1994). Medical praxis: An interface between ethics, politics, and technology. Social Science and Medicine (Oxford), 39, 1-5.

Lolas, F. (1996). Theoretical medicine: A proposal for reconceptualizing medicine as a science of actions. The Journal of Medicine and Philosophy, 21, 659-670.

Lolas, F. (1997a). Más allá del cuerpo. La construcción narrativa de la salud. Santiago: Andrés Bello.

Lolas, F. (1997b). Paul Christian y la escuela de Heidelberg. Nota prologal del libro Medicina antropológi$c a$ de Paul Christian (traducción y notas de F. Lolas). Santiago: Universitaria.

Lolas, F. (1998). Bioética. El diálogo moral en las ciencias de la vida. Santiago: Universitaria.

Lolas, F. (1999a). Antropología médica. Terceras Jornadas Argentino-
Chilenas de Medicina. Santiago: Instituto de Chile, 143-146.

Lolas, F. (1999b). Hacia una psiquiatría multidimensional. Investigación en Salud (Guadalajara, México), 1, 29-33.

Lolas, F. (2000a). Bioética y antropología médica. Santiago: Mediterráneo.

Lolas, F. (Ed.) (2000b). Bioética y cuidado de la salud. Equidad, calidad, derechos. Santiago: Programa Regional de Bioética, Organización Panamericana de la Salud.

Lolas, F. (2001). Paul Christian und die Heidelberger Schule. Fundamenta Psychiatrica, 15 (4), 135-138.

Lolas, F. (2002a). Bioética y medicina. Santiago: Biblioteca Americana.

Lolas, F. (2002b). Temas de bioética. Santiago: Universitaria.

Lolas, F. (2003). Psiquiatría y bioética. Monografias de Psiquiatría, Aula Médica. Año XV, núm. 3.

Lolas, F. (Ed.) (2004). Diálogo y cooperación en salud. Diez años de bioética en la OPS. Santiago: Unidad de Bioética OPS/OMS, Organización Panamericana de la Salud.

Lolas, F. \& Agar, L. (Eds.). (2002). Interfaces between bioethics and the empirical social sciences. Santiago: Programa Regional de Bioética, Organización Panamericana de la Salud. 
Lolas, F. \& Christian, P. (1990). Korrespondenztheorie: eine realwissenschaftliche Position bezüglich leib-seelische Zusammenhänge in der Psychosomatik. Zeitschrift für klinische Psychologie, Psychopathologie und Psychotherapie, 38, 146-154.
Lolas, F. \& Ferner, H. (1978). Zum Begriff des impliziten Verhaltens. Zeitschrift für klinische Psychologie und Psychotherapie, 26, 223-233.

Lolas, F. \& Mayer, H. (Eds.). (1987). Perspectives on stress-related topics. Berlín-Heidelberg-Nueva York: Springer-Verlag. 